\title{
A Simple Computational Tool for Accurate, Quantitative Prediction of One-Electron Reduction Potentials of Hypoxia-Activated Tirapazamine Analogues
}

\author{
Hassan R. H. Elsaidi, ${ }^{\mathrm{a}, \mathrm{b}}$ Leonard I Wiebe, ${ }^{\mathrm{a}, \mathrm{c}}$ Piyush Kumar ${ }^{\mathrm{a}}$ \\ ${ }^{a}$ Department of Oncology, Faculty of Medicine and Dentistry, University of Alberta, Edmonton, Alberta T6G 1Z2, Canada. \\ b Department of Pharmaceutical Chemistry, Faculty of Pharmacy, University of Alexandria, El Sultan Hussein St. Azarita, \\ Alexandria 21521, Egypt. ${ }^{c}$ Joint appointment to Faculty of Pharmacy and Pharmaceutical Sciences, University of Alberta, \\ Edmonton, Alberta T6G 2E1, Canada.
}

Received, March 23. 2020; Revised, April 30, 2020; Accepted, April 30, 2020; Published, May 2, 2020.

\begin{abstract}
The reduction potentials of bioreductively-activated drugs represent an important design parameter to be accommodated in the course of creating lead compounds and improving the efficacy of older generation drugs. Reduction potentials are traditionally reported as single-electron reduction potentials, $E(1)$, measured against reference electrodes under strictly defined experimental conditions. More recently, computational chemists have described redox properties in terms of a molecule's highest occupied molecular orbital (HOMO) and lowest unoccupied molecular orbital (LUMO), in electron volts (eV). The relative accessibility of HOMO/LUMO data through calculation using today's computer infrastructure and simplified algorithms make the calculated value (LUMO) attractive in comparison to the accepted but rigorous experimental determination of $E(1)$. This paper describes the correlations of eV (LUMO) to $E(1)$ for three series of bioreductively-activated benzotriazine di- $N$-oxides (BTDOs), ring-substituted BTDOs, ring-added BTDOs and a selection of aromatic nitro compounds. The current computational approach is a closed-shell calculation with a single optimization. Gas phase geometry optimization was followed by a single-point DFT (Density Functional Theory) energy calculation in the gas phase or in the presence of polar solvent. The resulting DFT-derived LUMO energies (eV) calculated for BTDO analogues in gas phase and in presence of polar solvent (water) exhibited very strong linear correlations with high computational efficiency $\left(r^{2}=0.9925\right)$ and a very high predictive ability $(\mathrm{MAD}=7 \mathrm{mV}$ and RMSD $=$ $9 \mathrm{mV}$ ) when compared to reported experimentally determined single-electron reduction potentials.
\end{abstract}

Keywords: Hypoxia-activated prodrugs, BTDOs, reduction potential, quantitative computational model.

\section{INTRODUCTION}

Focal hypoxia is caused by microenvironmental deficiency of oxygen as a direct result of the rapid growth and aberrant vasculatures in most solid tumors. As a malicious metabolic aberration, tumor hypoxia enhances the potential for cancer metastasis, treatment failure and hypoxia-based radio- and chemotherapy resistance as compared to oxygenated tumors. Taken together, hypoxia-induced molecular aberrations are major obstacles for effective tumor management [1-5]. The main basis of hypoxic tumor radiosensitization therapy has been the utilization of electron-affinic organic compounds that are bioreductively-activated selectively in hypoxic microenvironments to induce radiation-like molecular damage similar to what happens in presence of oxygen [7-10]. Of these compounds, tirapazamine (TPZ; Fig.1) is a benzotriazine di- $N$ oxide (BTDO) that has been subjected to extensive preclinical and clinical studies as a radiosensitizer [10]. TPZ requires a single-electron bioreductive activation [11-13] to produce free radicals which in turn induce single and double strand breaks in DNA, exploiting the hypoxic microenvironment to be selectively cytotoxic to solid hypoxic tumors (Fig. 1) [13-17].

Corresponding Authors: Hassan R. H. Elsaidi, Department of Pharmaceutical Chemistry, Faculty of Pharmacy, University of Alexandria, El Sultan Hussein St. Azarita, Alexandria 21521, Egypt (elsaidi@ualberta.ca) or Piyush Kumar (pkumar@ualberta.ca), Department of Oncology, Faculty of Medicine and Dentistry, University of Alberta, 11560 University Avenue Edmonton, Alberta, Canada. 


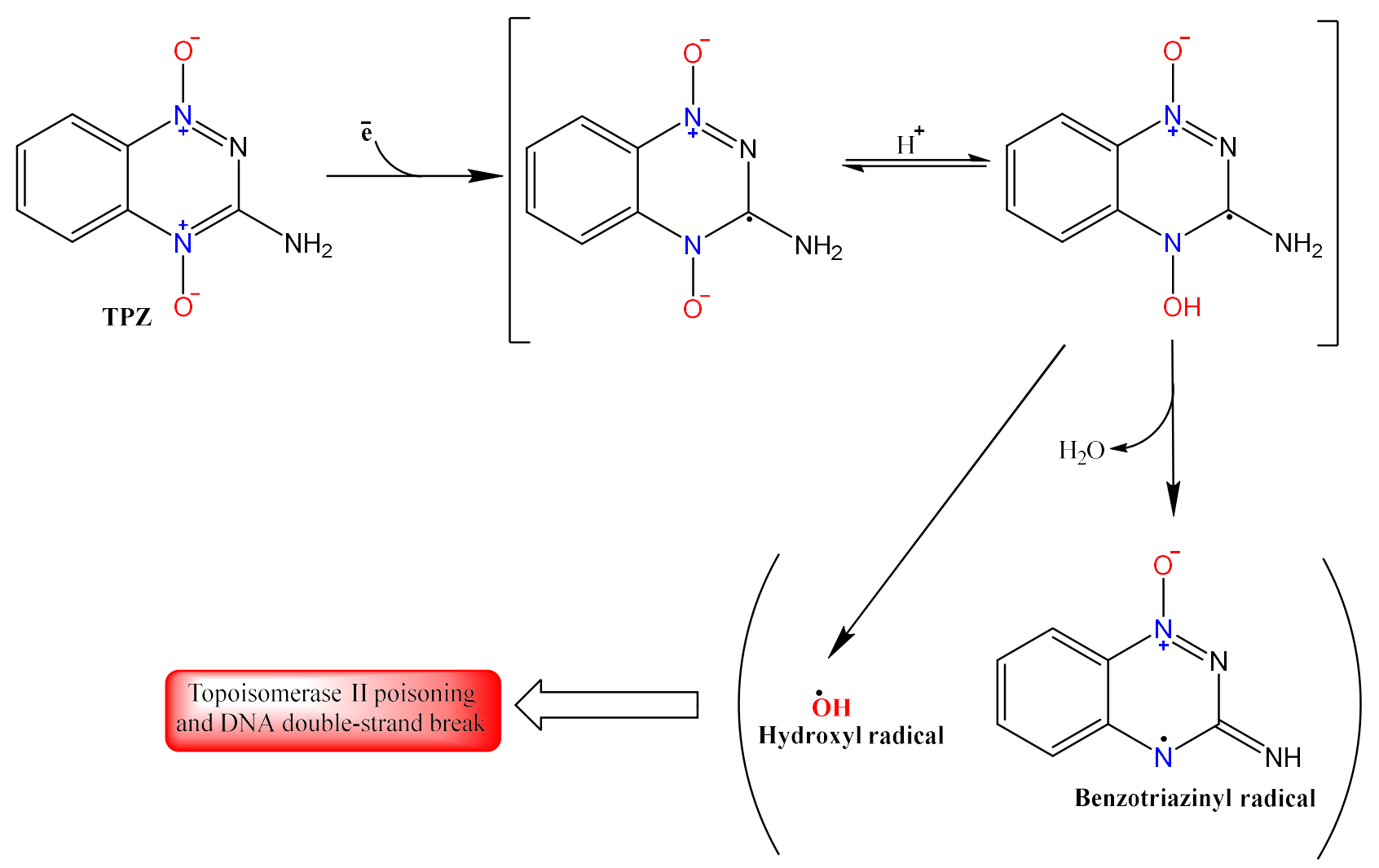

Figure 1. Mechanism of TPZ-mediated hypoxia-selective cytotoxicity.

Despite the initial clinical success of TPZ in conjunction with radiation therapy for the management of hypoxic tumor, the poor extravascular transport (EVT) of TPZ to the tumor site was a major limitation. The first-electron reduction potential, $E(1)$, and the partition coefficient $(\log P)$ are the two physico-chemical properties that directly influence the rate of hypoxic metabolism and EVT, respectively, of TPZ and TPZ-analogues, processes that are necessary to achieve effective chemical concentrations in vivo for radiosensitization therapy [18-20].

To overcome the poor EVT of TPZ, several TPZ-analogues have been synthesized in attempts to optimize the balance between $E(1)$ and $\log P$ that would improve hypoxia-induced radiosensitization and antiproliferative effects [21-28]. Recently, there is an increasing interest in exploiting the hypoxiaselective properties of TPZ to develop molecular theranostics of hypoxia $[26,27,29]$ and to repurpose TPZ-analogues for treatment of serious anerobic bacterial infection such as E. coli, $S$. aureus, $C$. difficile [30] and M. tuberculosis [31]. In drug discovery, the TPZ-analogues are typically synthesized first and then their experimentally- derived $E(1)$ is measured, a protocol that is timeconsuming, expensive and labor-intensive. Ideally, an optimized computational method that can accurately predict the reduction potentials of the bioreductive drugs, in the current context the proposed TPZ-analogues, would guide medicinal chemists in the process of decision making by selecting only those compounds that show favourable theoretically-predicted reduction potentials. Based on their $E(1)$, potentially active molecules can be selected for full synthesis development and complete biological evaluation, which may substantially enhance an otherwise ineffective drug development approach.

A good linear correlation between the Hückelcalculated LUMO (lowest unoccupied molecular orbital) energies and the experimentally-derived reduction potentials of hydrocarbons was first demonstrated by Maccoll in 1949 [32]. This finding prompted extensive research in the field of computational chemistry, with the purpose of finding better computational methods that include both the solvent stabilisation and molecular reorganizational energies in the calculation of LUMO energies, which Maccoll's method excluded. Interested researchers 
are referred to selected papers for more detailed information [33-39]. It is noteworthy to mention that both Fry et al [37] and Gillmore et al [38] have provided good computational methods for accurately predicting the redox potentials of mainly polycyclic aromatic hydrocarbons (PAHs), expanded to few other classes in case of Gillmore's method [39], with good correlation to the experimentally-derived reduction potentials. Despite both methods having been proven to provide accurate values, they are computationally expensive and require an experienced computational chemist, as they rely on three [38] to six [37] calculations per molecule. The high computational cost and complexity of both methods were resolved by Mujica et al [40]. These authors reported a simple computational method that accurately correlates DFT (Density Functional Theory)-calculated HOMO (highest occupied molecular orbital) /LUMO energies (HLE) to the experimentally-derived redox potentials through a single point calculation per molecule using B3LYP/6-31G(d) functional. This method provided good correlation between the DFT-calculated HOMO/LUMO energies and the redox potentials of 51 PAHs, as well as to other organic compounds of different structural families [41]. Despite the accuracy and efficiency of this method, a linear correlation must be established and calibrated before any prediction can be made. Therefore, Mujica et al suggested that new correlations should be established for other structural families of compounds, functional groups or solvents to maintain accurate predictability, especially because most compounds used in their methodology were rigid organic compounds [40].

Our special interest is to design new TPZanalogues as theranostic tools for management of hypoxia and treatment of anaerobic bacterial infections. The aim of this work is to exploit a quantitative tool to predict the reduction potentials of newly proposed molecules that is accurate, fast, cost-efficient and simple enough to be conducted in medicinal chemistry laboratories. With this purpose in mind, the implementation, calibration and application of a linear correlation between the DFTcalculated LUMO energies and experimental first electron reduction potentials using the method reported by Mujica et al are now reported for a series of TPZ and nitroimidazole analogues.

\section{Computational Method}

All calculations were done on an HP Envy Phoenix $810-160$ with $4^{\text {th }}$ generation Intel ${ }^{\circledR}$ Core $17-4770$ processor, 16GB of DDR3 system memory and 16 GB SATA 6G SSD acceleration cache. Spartan 16 Parallel Suit (Wavefunction Inc., Irvine CA) was used for optimization of the calibrant molecules $[42,43]$. Molecules 1-64 were constructed using the 3D model kit of the program and preliminarily minimized by the program's comprehensive molecular mechanics tool. These structures were subsequently submitted to geometry optimization in gas phase and followed by single-point energy calculation in gas phase and in polar solvent (water). The Conductor-like Polarizable Continuum Model (CPCM) [44,45] was employed in calculations involving polar solvent (water). All calculations were carried out at DF level of theory with the B3LYP [46,47] hybrid density functional and 631G(d) [48-50] basis set. Geometry optimization and single-point energy calculations were performed in a single step using the intuitive graphical user interface (GUI) of Spartan 16 Parallel Suit.

\section{RESULTS AND DISCUSSION}

The experimental $E(1)$ values for tirapazamine analogues $(\mathbf{1}-\mathbf{6 4}$, Tables $1-4)$ were obtained from the literature [21-24]. The E(1) experiments are usually conducted in anaerobic aqueous solution at $\mathrm{pH} 7$ by measuring the one-electron transfer equilibrium constants between the radical anions of the test compounds and a reference standard (viologen or quinone), with compensation for the effect of ionic strength on the equilibrium constant by collecting the data at three concentration ratios at room temperature $\left(22 \pm 2{ }^{\circ} \mathrm{C}\right)$ and using them to calculate the $\Delta E$ between the test compounds and the appropriate reference [24,51,52].

The DFT-calculated LUMO energies of compounds 1-64, calculated for the gas phase and for the presence of polar solvent (water), were plotted against their experimental $E(1)$ values to construct linear correlations, Figure 2. A summary of the parameters of the linear correlations between the computed LUMO energies and the experimental $E(1)$ values established in the current study is provided in Table 5 . 

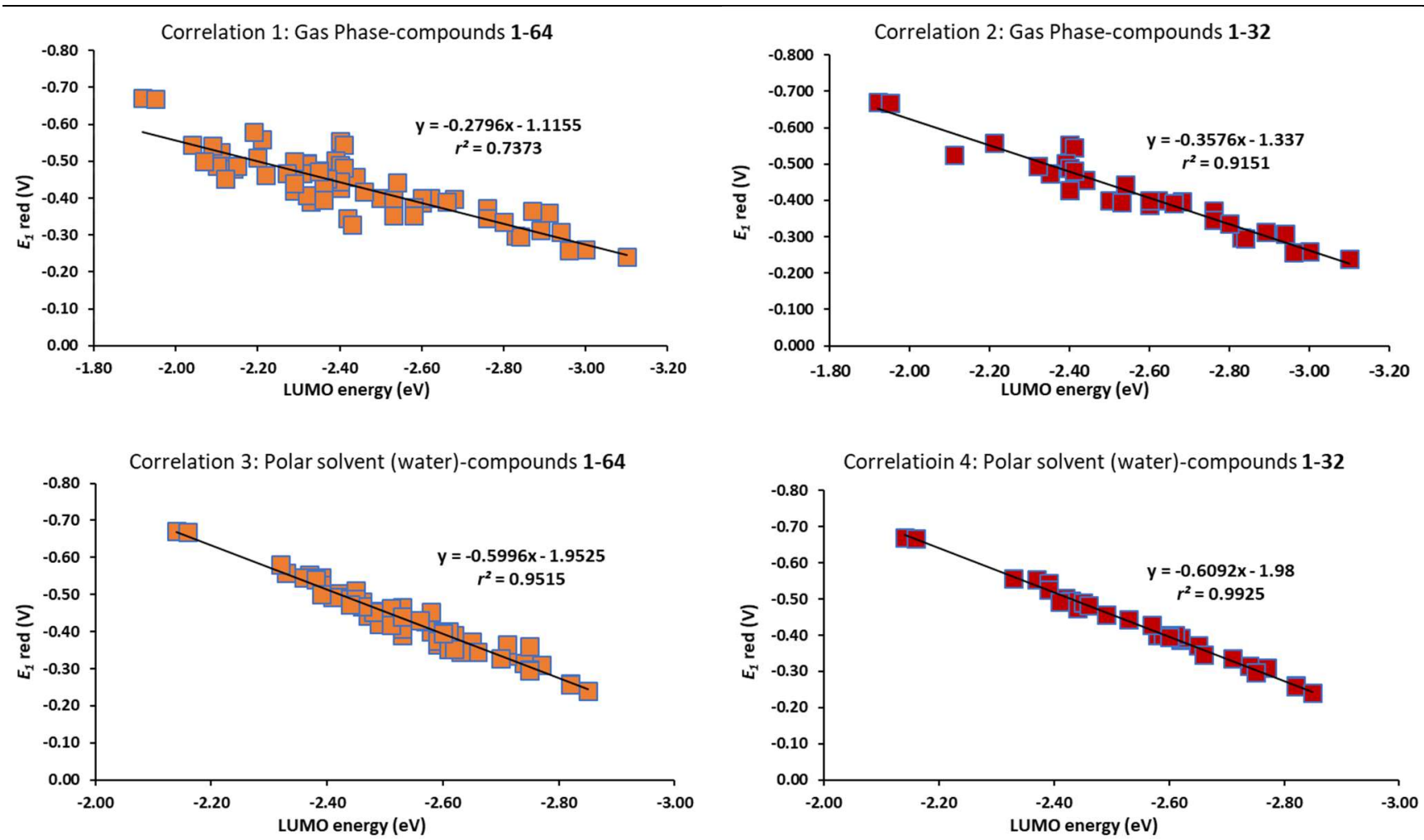

Figure 2. Plots of linear correlations between the computed LUMO energies (eV), in gas phase and in the presence of polar solvent, vs. the experimental $E(1)$ values, (V), of compounds 1-64.

Table 1. Chemical structures, published experimental E(1) values [21], and computed LUMO energies for compounds 1-32.<smiles>[R]c1c([R])c([R])c2c(c1[R])[n+]([O-])nc(N)[n+]2[O-]</smiles>

\begin{tabular}{|c|c|c|c|c|c|c|c|}
\hline$\underset{\#}{\text { Comp. }}$ & $\mathbf{R}^{1}$ & $\mathbf{R}^{2}$ & $\begin{array}{l}1-32 \\
\mathbf{R}^{3}\end{array}$ & $\mathbf{R}^{4}$ & $\begin{array}{c}E 1 \\
(V)^{*}\end{array}$ & $\begin{array}{c}\text { LUMO Energy } \\
(\mathrm{eV}) / \text { Gas Phase** }\end{array}$ & $\begin{array}{c}\text { LUMO Energy }(\mathrm{eV}) / \\
\text { Polar Solvent } \\
\left(\mathrm{H}_{2} \mathrm{O}\right)^{* *}\end{array}$ \\
\hline 1 & $\mathrm{H}$ & $\mathrm{H}$ & $\mathrm{H}$ & $\mathrm{H}$ & -0.456 & -2.44 & -2.49 \\
\hline 3 & $(\mathrm{Me})_{2} \mathrm{~N}$ & $\mathrm{H}$ & $\mathrm{H}$ & $\mathrm{H}$ & -0.545 & -2.41 & -2.37 \\
\hline 4 & $\mathrm{OCH}_{3}$ & $\mathrm{H}$ & $\mathrm{H}$ & $\mathrm{H}$ & -0.503 & -2.39 & -2.42 \\
\hline 5 & $\mathrm{~F}$ & $\mathrm{H}$ & $\mathrm{H}$ & $\mathrm{H}$ & -0.400 & -2.50 & -2.58 \\
\hline 7 & $\mathrm{CF}_{3}$ & $\mathrm{H}$ & $\mathrm{H}$ & $\mathrm{H}$ & -0.372 & -2.76 & -2.65 \\
\hline 8 & $\mathrm{SO}_{2} \mathrm{CH}_{3}$ & $\mathrm{H}$ & $\mathrm{H}$ & $\mathrm{H}$ & -0.309 & -2.94 & -2.77 \\
\hline 9 & $\mathrm{SO}_{2} \mathrm{Bu}$ & $\mathrm{H}$ & $\mathrm{H}$ & $\mathrm{H}$ & -0.314 & -2.89 & -2.74 \\
\hline 10 & $\mathrm{H}$ & $(\mathrm{Me})_{2} \mathrm{~N}$ & $\mathrm{H}$ & $\mathrm{H}$ & -0.525 & -2.11 & -2.39 \\
\hline 11 & $\mathrm{H}$ & $\mathrm{OCH}_{3}$ & $\mathrm{H}$ & $\mathrm{H}$ & -0.494 & -2.32 & -2.43 \\
\hline
\end{tabular}


Table 1. Continued...

\begin{tabular}{|c|c|c|c|c|c|c|c|}
\hline 12 & $\mathrm{H}$ & $\mathrm{CH}_{3}$ & $\mathrm{H}$ & $\mathrm{H}$ & -0.474 & -2.35 & -2.44 \\
\hline 13 & $\mathrm{H}$ & $\mathrm{F}$ & $\mathrm{H}$ & $\mathrm{H}$ & -0.400 & -2.62 & -2.59 \\
\hline 14 & $\mathrm{H}$ & $\mathrm{Cl}$ & $\mathrm{H}$ & $\mathrm{H}$ & -0.397 & -2.68 & -2.60 \\
\hline 15 & $\mathrm{H}$ & $\mathrm{CF}_{3}$ & $\mathrm{H}$ & $\mathrm{H}$ & -0.345 & -2.76 & -2.66 \\
\hline 17 & $\mathrm{H}$ & $\mathrm{SO}_{2} \mathrm{Bu}$ & $\mathrm{H}$ & $\mathrm{H}$ & -0.296 & -2.84 & -2.75 \\
\hline 18 & $\mathrm{H}$ & $\mathrm{NO}_{2}$ & $\mathrm{H}$ & $\mathrm{H}$ & -0.260 & -3.00 & -2.82 \\
\hline 21 & $\mathrm{H}$ & $\mathrm{H}$ & $\mathrm{OCH}_{3}$ & $\mathrm{H}$ & -0.558 & -2.21 & -2.33 \\
\hline 22 & $\mathrm{H}$ & $\mathrm{H}$ & $\mathrm{CH}_{3}$ & $\mathrm{H}$ & -0.493 & -2.32 & -2.41 \\
\hline 23 & $\mathrm{H}$ & $\mathrm{H}$ & $\mathrm{F}$ & $\mathrm{H}$ & -0.443 & -2.54 & -2.53 \\
\hline 24 & $\mathrm{H}$ & $\mathrm{H}$ & $\mathrm{Cl}$ & $\mathrm{H}$ & -0.391 & -2.66 & -2.62 \\
\hline 25 & $\mathrm{H}$ & $\mathrm{H}$ & $\mathrm{CF}_{3}$ & $\mathrm{H}$ & -0.335 & -2.80 & -2.71 \\
\hline 30 & $\mathrm{H}$ & $\mathrm{H}$ & $\mathrm{H}$ & $\mathrm{OCH}_{3}$ & -0.427 & -2.40 & -2.57 \\
\hline 31 & $\mathrm{H}$ & $\mathrm{H}$ & $\mathrm{H}$ & $\mathrm{Cl}$ & -0.401 & -2.60 & -2.61 \\
\hline 32 & $\mathrm{H}$ & $\mathrm{H}$ & $\mathrm{H}$ & $\mathrm{F}$ & -0.394 & -2.53 & -2.60 \\
\hline
\end{tabular}

Table 2. Chemical structures, reported experimental $E 1$ values [22], and computed LUMO energies for compounds 33-36.

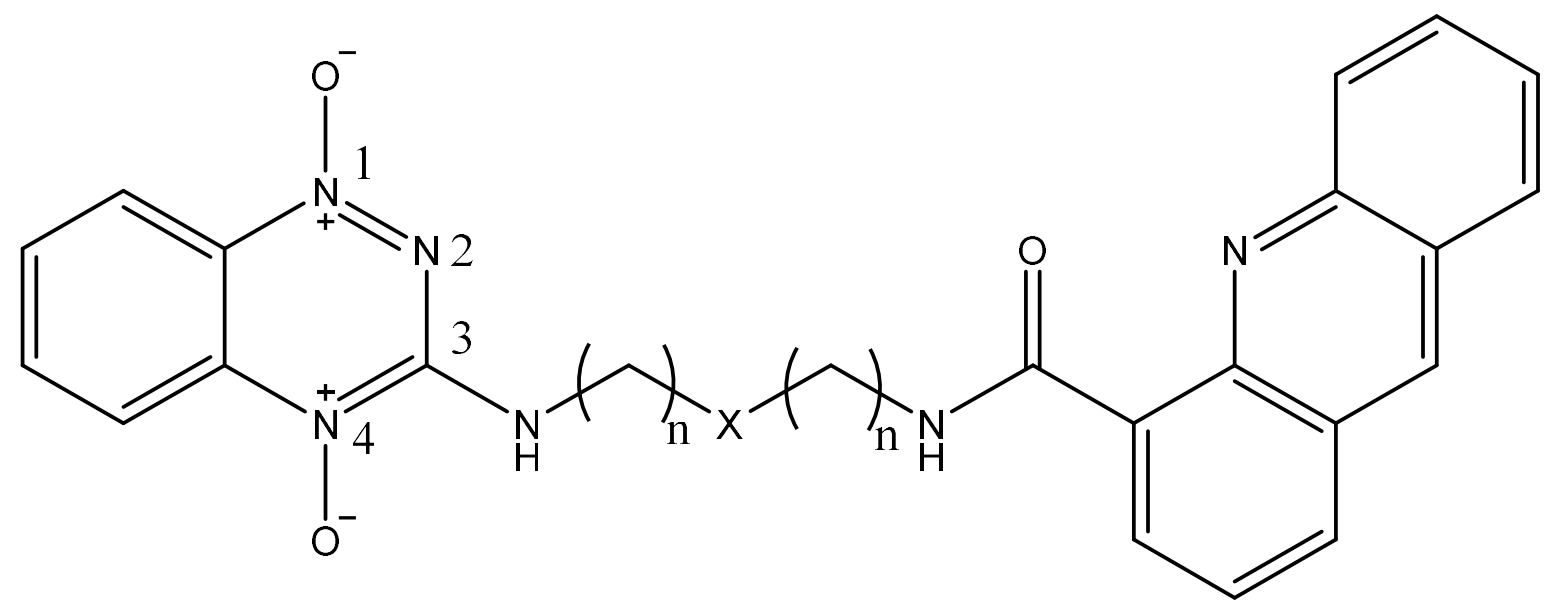

33-36

\begin{tabular}{ccccccc} 
Compd. \# & $\mathbf{X}$ & $\mathbf{n}$ & Oxide & $\boldsymbol{E 1}(\mathbf{V}) *$ & $\begin{array}{c}\text { LUMO Energy (eV)/ } \\
\text { Gas Phase** }\end{array}$ & $\begin{array}{c}\text { LUMO Energy (eV)/ } \\
\text { Polar Solvent (HoO)** }\end{array}$ \\
\hline $\mathbf{3 3}$ & $\mathrm{NCH}_{3}$ & 3 & 1,4-dioxide & -0.444 & -2.4 & -2.47 \\
$\mathbf{3 4}$ & $\mathrm{NH}$ & 3 & 1,4-dioxide & -0.421 & -2.29 & -2.49 \\
$\mathbf{3 5}$ & $\mathrm{O}$ & 2 & 1,4-dioxide & -0.466 & -2.31 & -2.53 \\
$\mathbf{3 6}$ & $\mathrm{NCH}_{3}$ & 3 & 1-oxide & -0.580 & -2.19 & -2.32 \\
\hline *published, **new data &
\end{tabular}


Table 3. Chemical structures, published experimental E1 values [23], and computed LUMO energies for compounds 37-52.

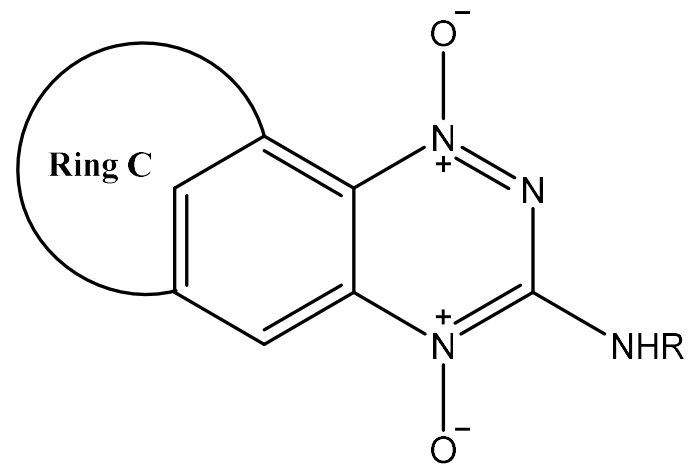

37-52

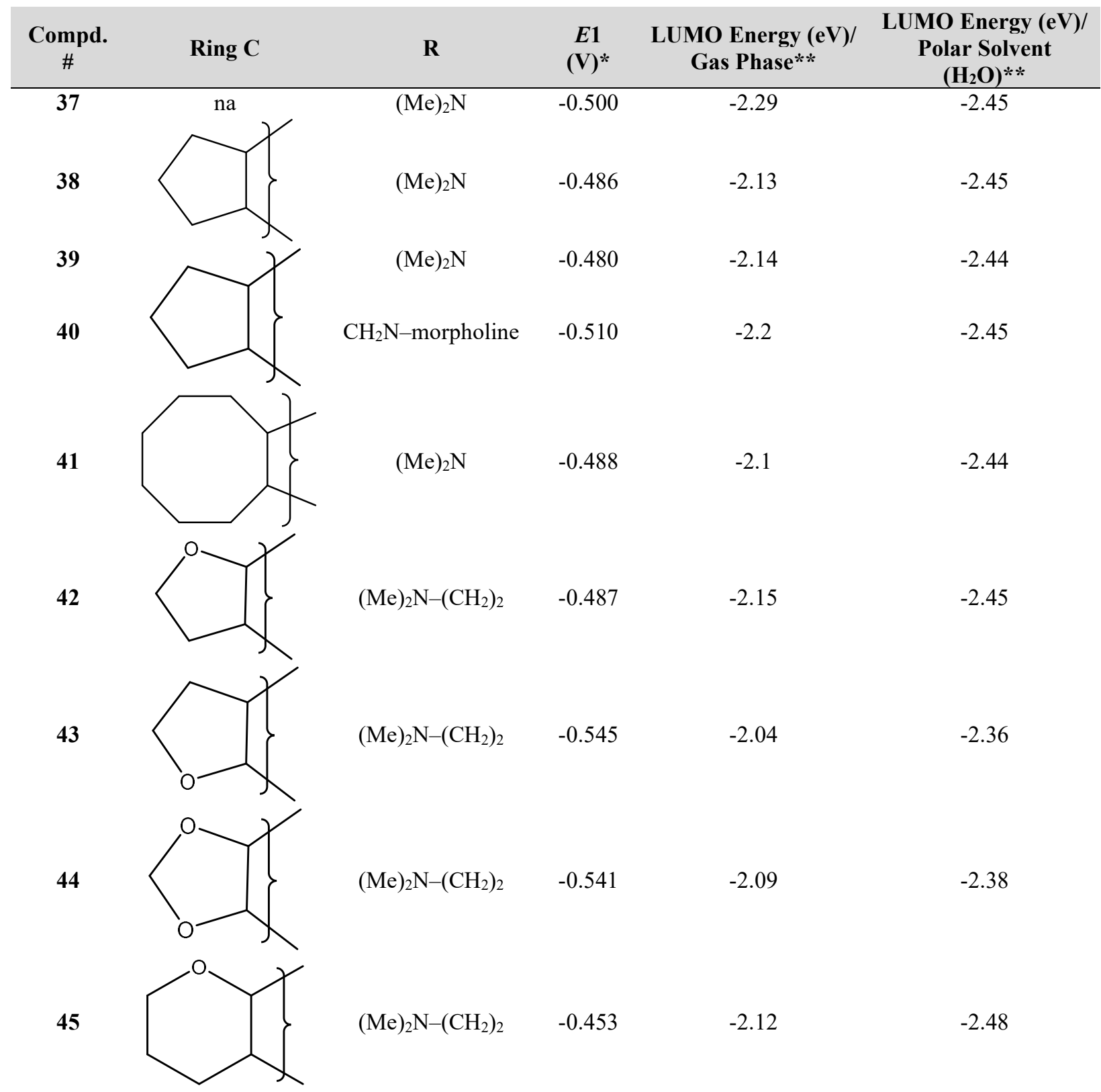


Table 3. Continued...

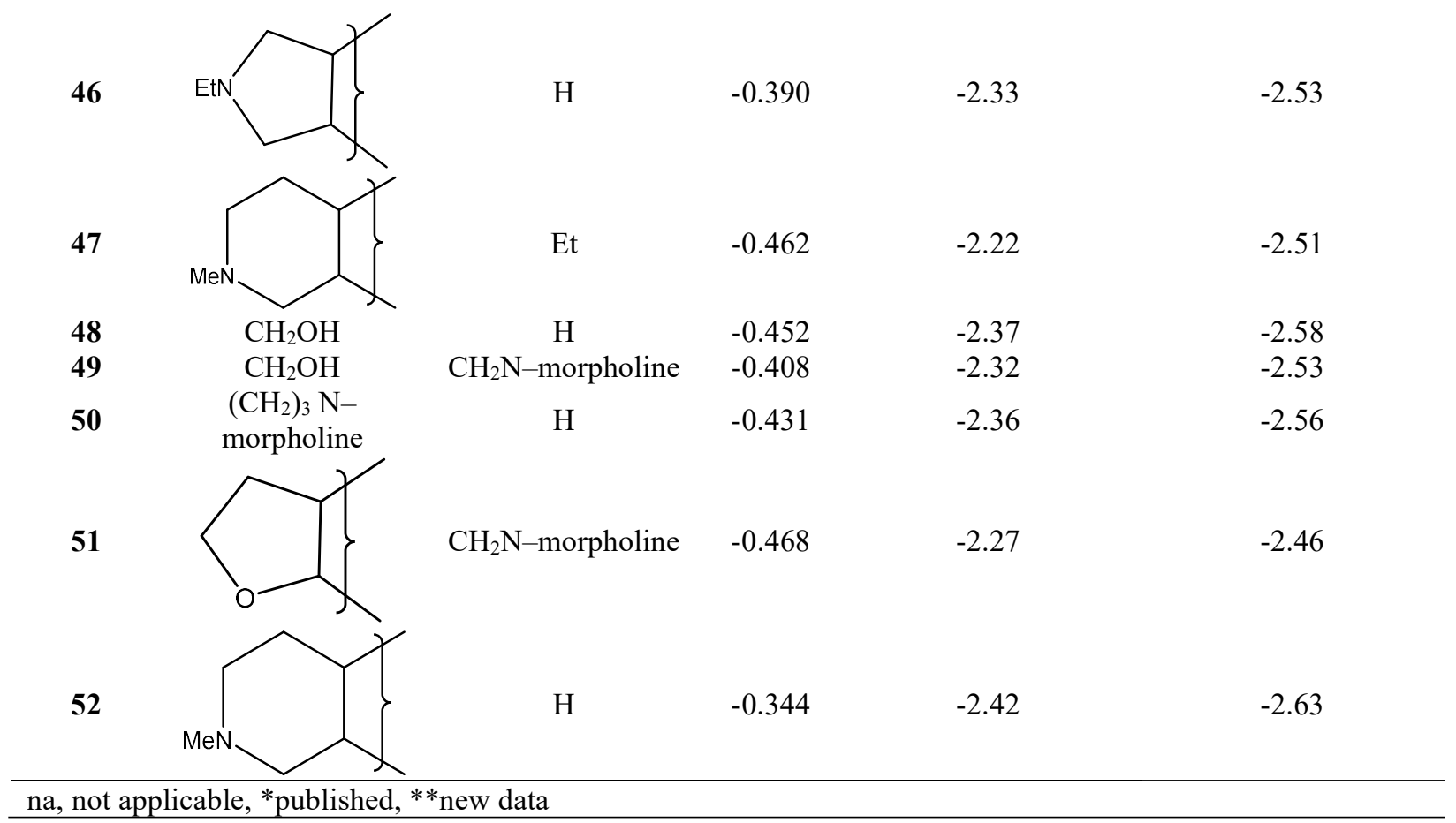

Table 4. Chemical structures, experimental $E(1)$ values [24] and computed LUMO energies for compounds $\mathbf{3 7 - 5 2 .}$

\begin{tabular}{|c|c|c|c|c|c|}
\hline $\begin{array}{c}\text { Compd. } \\
\# \\
\end{array}$ & $\mathbf{R}^{1}$ & $\mathbf{R}^{2}$ & $E 1(V) *$ & $\begin{array}{c}\text { LUMO Energy } \\
(\mathrm{eV}) / \text { Gas Phase** }\end{array}$ & $\begin{array}{l}\text { LUMO Energy }(\mathrm{eV}) / \\
\text { Polar Solvent }\left(\mathrm{H}_{2} \mathrm{O}\right) * * \\
\end{array}$ \\
\hline 53 & $-\mathrm{CH}_{3}$ & $\mathrm{H}$ & -0.364 & -2.58 & -2.59 \\
\hline 54 & $-\mathrm{CH}_{2} \mathrm{CH}_{3}$ & $\mathrm{H}$ & -0.376 & -2.58 & -2.59 \\
\hline 55 & $-\left(\mathrm{CH}_{2}\right)_{2}-\mathrm{OCH}_{3}$ & $\mathrm{H}$ & -0.353 & -2.53 & -2.61 \\
\hline 56 & $-\left(\mathrm{CH}_{2}\right)_{2}-\mathrm{OH}$ & $\mathrm{H}$ & -0.360 & -2.91 & -2.75 \\
\hline 57 & $-\left(\mathrm{CH}_{2}\right)_{3}-\mathrm{OH}$ & $\mathrm{H}$ & -0.364 & -2.87 & -2.71 \\
\hline 58 & $-\mathrm{C}_{4} \mathrm{H}_{6}$ & $\mathrm{H}$ & -0.352 & -2.58 & -2.62 \\
\hline 59 & $-\left(\mathrm{CH}_{2}\right)_{2}-\mathrm{N}\left(\mathrm{CH}_{3}\right)_{2}$ & $\mathrm{H}$ & -0.327 & -2.43 & -2.6 \\
\hline 60 & $\begin{array}{c}\mathrm{NH}- \\
\left(\mathrm{CH}_{2}\right)_{2} \mathrm{~N}\left(\mathrm{CH}_{3}\right)_{2}\end{array}$ & $6-\mathrm{CH}_{3} \mathrm{O}-$ & -0.500 & -2.07 & -2.39 \\
\hline 61 & $-\mathrm{CH}_{2} \mathrm{CH}_{3}$ & $6-\mathrm{CH}_{3}-$ & -0.418 & -2.46 & -2.51 \\
\hline 62 & $-\mathrm{CH}_{2} \mathrm{CH}_{3}$ & $6-\mathrm{CH}_{3} \mathrm{O}-$ & -0.472 & -2.35 & -2.44 \\
\hline 63 & $-\mathrm{CH}_{2} \mathrm{CH}_{3}$ & $\begin{array}{l}\text { 6-morpholine-N- } \\
\quad\left(\mathrm{CH}_{2}\right)_{3}-\mathrm{O}-\end{array}$ & -0.440 & -2.29 & -2.43 \\
\hline 64 & $-\mathrm{CH}_{2} \mathrm{CH}_{3}$ & $\begin{array}{c}\text { 7-morpholine-N- } \\
\left(\mathrm{CH}_{2}\right)_{3}-\mathrm{O}- \\
\end{array}$ & -0.396 & -2.36 & -2.5 \\
\hline
\end{tabular}




\begin{tabular}{|c|c|c|c|c|c|c|c|}
\hline \# & $\begin{array}{c}\text { Calculation } \\
\text { type }\end{array}$ & $r^{2}$ & $\begin{array}{c}\text { MAD }^{\mathrm{a}} \\
\text { residuals (V) }\end{array}$ & $\begin{array}{c}\text { RMSD }^{\mathbf{b}} \\
\text { residuals (V) }\end{array}$ & $\begin{array}{c}\text { Slope } m \\
(V / e V)\end{array}$ & $\begin{array}{c}\mathrm{X} \text {-intercept } \\
(\mathrm{eV})\end{array}$ & $\begin{array}{c}\text { Y-intercept } \\
\text { (V) }\end{array}$ \\
\hline 1 & $\begin{array}{l}\text { Gas Phase } \\
\text { (1-64) }\end{array}$ & 0.7373 & 0.034816 & 0.186590 & -0.28237 & -3.989628 & -1.1155 \\
\hline 2 & $\begin{array}{c}\text { Gas Phase } \\
(\mathbf{1 - 3 2})\end{array}$ & 0.9151 & 0.022061 & 0.028973 & -0.3576 & -3.738814 & -1.3370 \\
\hline 3 & $\begin{array}{c}\text { C-PCM (water) } \\
(\mathbf{1 - 6 4 )}\end{array}$ & 0.9515 & 0.014760 & 0.019662 & -0.59960 & -3.256338 & -1.952500 \\
\hline 4 & $\begin{array}{c}\text { C-PCM (water) } \\
(\mathbf{1 - 3 2})\end{array}$ & 0.9925 & 0.007272 & 0.009389 & -0.60920 & -3.250164 & -1.98000 \\
\hline
\end{tabular}

${ }^{a}$ Mean average deviation calculated from individual residuals for each compound as predicted by the trend line (Supporting Information). ${ }^{b}$ Root mean square deviation calculated from individual residuals for each compound as predicted by the trend line (Supporting Information)

Four linear correlations between the DFTcomputed LUMO energies and the experimental $E(1)$ were established in the current study. Correlation \#1, between the DFT-calculated LUMO energies of all calibrant compounds (1-64) and their experimental $E(1)$ values in gas phase, resulted in low $r^{2}$ (0.737), indicative of low computational efficiency. Correlation \#3 included the solvent in the calculation, which improved the $r^{2}(0.951)$. This variance is due to the absence of the solvent stabilization effect on compounds 1-64 in gas phase calculations, which span a wide range of structural substitutions in the tirapazamine parent structure that in turn induce various levels of structural flexibility and therefore different solvent reorganization energies [39]. It is noteworthy that Correlation \#2 for compounds 1-32 yielded an higher $r^{2}(0.915)$ for the gas phase calculation, an effect primarily due to the similar solvent reorganization energies of compounds 1-32, as they differ only in the substitution pattern of the aromatic ring of the tirapazamine parent structure. The substitution pattern imparts only a limited effect on the structural flexibility of these molecules, and hence the error associated with not including the solvent in the calculation is very small. Furthermore, when the solvent was included in the calculation for compounds 1-32 (correlation \#4), the $r^{2}$ was greatly improved, approaching the optimal value of 1 (0.9925), demonstrating high computational efficiency and high predictive ability as reflected in the very small values of MAD and RMSD. To further test and establish the predictive ability of the current method, Correlation \#4, which demonstrated the strongest correlation in the current study, was used to predict the reduction potentials of five test compounds, 65-69 [53] that were not included in the data set used to establish these correlations (Figure $3)$. Furthermore, test compounds are not structurally related to TPZ; $65-67$ are 5-nitroimidazoles, 68 is a 2-nitrofuran and 69 is a 2-nitroimidazole. The experimental one-electron reduction potentials $E(1)$ of these test compounds were determined at $\mathrm{pH} 7$ in aqueous solution using pulse radiolysis [7]. The predicted $E(1)$ values calculated from Correlation \#4 for the test compounds were very close to the experimental values, providing a further demonstration of the robust predictive ability of this correlation (Table 6).

\section{CONCLUSION}

These analytical data show that a very strong linear correlation between the DFT-calculated LUMO energies and the experimental $E(1) \mathrm{s}$ of TPZ analogues can be established using a polar solvent model. The established correlation has a high computational efficiency $\left(r^{2}=0.9925\right)$ and a very high predictive ability (MAD $=7 \mathrm{mV}$ and $\mathrm{RMSD}=$ $9 \mathrm{mV}$ ), which can be extended to other hypoxiaselective compounds, e.g., 65-69, that are structurally unrelated to TPZ. The current methodology used a closed-shell calculation and a single optimization. Gas phase geometry optimization followed by a single-point energy calculation for the presence of polar solvent reduced both the number and the complexity of the computations.

In conclusion, this approach provides a simple, quick and accurate quantitative method to predict reduction potential without requiring the skills, computing resources and expense normally associated with molecular computation. By removing the necessity for a strong background in 
computational chemistry and the knowledge of complex computational protocols, our objective is to encourage medicinal chemists to exploit computational tools through easy-to-use graphical user interfaces. This can accelerate research in drug discovery and optimization, and as applied in this case, lead to better management of hypoxia.

\section{ACKNOWLEDGEMENTS}

This work was supported through grants 201201164 and 20131051 from Alberta Innovates through the CRIO program and CRIO Project-Cancer.

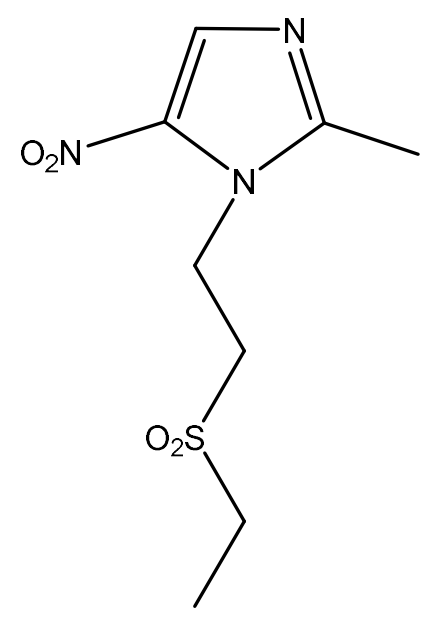

65, Tinidazole

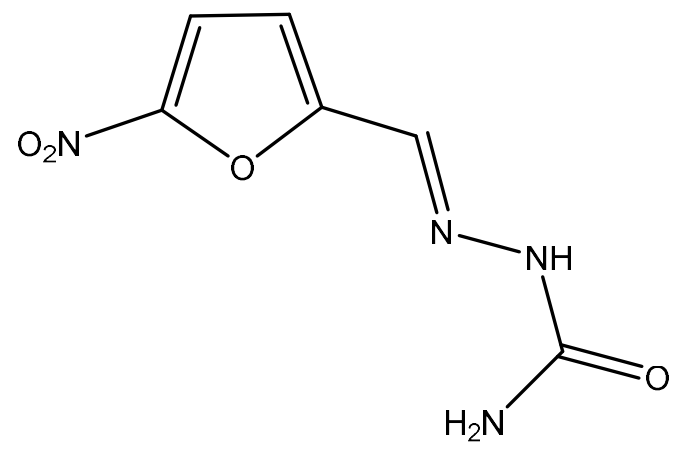

68, Nitrofurazone
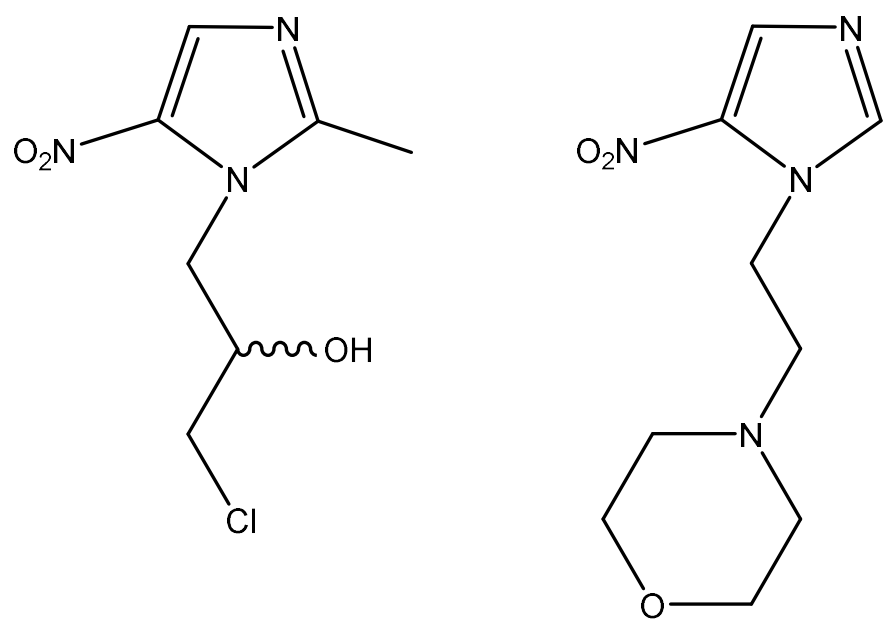

66, Ornidazole

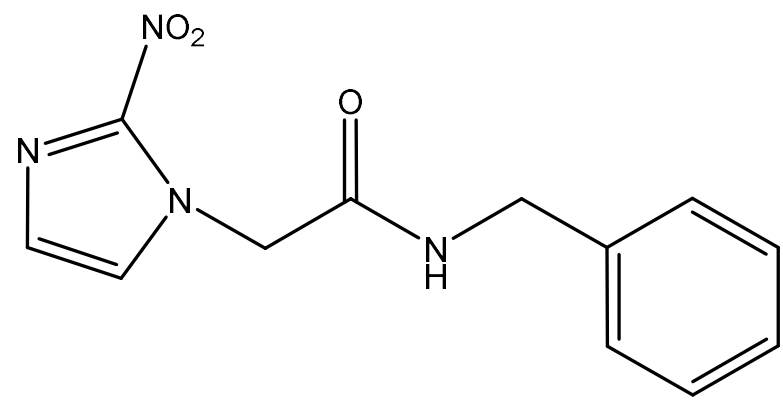

69, Benznidazole

Figure 3. Structures of test compounds 65-69.

\begin{tabular}{ccccc}
\multicolumn{6}{c}{ Table 6. Experimental and predicted $E(1)$ values $[53]$ and computed LUMO energies for test compounds 65-69. } \\
\hline Compound \# & Correlation \# & $\begin{array}{c}\text { LUMO } \\
(\mathbf{e V})^{*}\end{array}$ & Experimental $\boldsymbol{E}(\mathbf{1})(\mathbf{V})^{* *}$ & Predicted $\boldsymbol{E}(\mathbf{1})(\mathbf{V})$ * \\
\hline $\mathbf{6 5}$ & 4 & -2.48 & -0.464 & -0.469 \\
$\mathbf{6 6}$ & 4 & -2.47 & -0.467 & -0.475 \\
$\mathbf{6 7}$ & 4 & -2.51 & -0.457 & -0.450 \\
$\mathbf{6 8}$ & 4 & -2.82 & -0.257 & -0.262 \\
$\mathbf{6 9}$ & 4 & -2.62 & -0.380 & -0.384 \\
\hline
\end{tabular}

*new, **published data 


\section{REFERENCES}

1. Vaupel P, Mayer A. Hypoxia in cancer: Significance and impact on clinical outcome. Cancer Metast. Rev, 2007; 26:225-239.

2. Masson N, Ratcliffe PJ. Hypoxia signaling pathways in cancer metabolism: the importance of co-selecting interconnected physiological pathways. Cancer Metab, 2014; 2:3-20.

3. Span PN, Bussink J. Biology of hypoxia, 2015; 45:101-109.

4. Challapalli A, Carroll L, Aboagye EO. Molecular mechanisms of hypoxia in cancer. Clin Transl Imaging, 2017; 5:225-253.

5. Kim JY, J.Y. Lee JY. Targeting tumor adaption to chronic hypoxia: Implications for drug resistance, and how it can be overcome. Int J Mol Sci, 2017; 118:1854.

6. Adams GE, Clarke ED, Jacobs RS, Stratford IJ, Wallace RG, Wardman P, Watts ME. Mammalian cell toxicity of nitro compounds: dependence upon reduction potential. Biochem Biophys Res Commun, 1976; 72:824-829.

7. Adams GE, Flockhart IR, Smithen CE, Stratford IJ, Wardman P, Watts ME. Electron-affinic sensitization. VII. A correlation between structure, one-electron reduction potentials and efficiencies of nitroimidazoles as hypoxic cell radiosensitizers. Radiat Res, 1976; 67:9-20.

8. Adams GE, Cooke MS. Electron-affinic sensitization. I. A structural basis for chemical radiosensitizers in bacteria. Int $\mathrm{J}$ Radiat Biol, 1969; 15:457-471.

9. Toustrup K, Sorenson BS, Lassen P, Wiuf C, Alsner J, Overgaard J. Gene expression classifier predicts for hypoxic modification of radiotherapy with nimorazole in squamous cell carcinomas of the head and neck. Radiother Oncol, 2012; 102:122-129.

10. Zeman EM, Brown JM, Lemmon MJ, Hirst VK, Lee WW. SR-4233: a new bioreductive agent with high selective toxicity for hypoxic mammalian cells. Int J Radiat Oncol Biol Physics, 1986; 12:1239-1242.

11. Brown JM. SR 4233 (Tirapazamine): a new anticancer drug exploiting hypoxia in solid tumors. Brit J. Cancer, 1993; 67:1163-1170.

12. Wilson WRW, Hay MPM. Targeting hypoxia in cancer therapy. Nat Rev Cancer, 2011; 11:393-410.

13. Moriwaki T, Okamoto S, Sasanuma H, Nagasawa H, Takeda S, Masunaga S-I, Tano K. Cytotoxicity of tirapazamine (3-amino-1,2,4-benzotriazine-1,4dioxide)-induced DNA damage in chicken DT40 cells. Chem Res Toxicol, 2016; 30:699-704.

14. Jones GDD, Weinfeld M. Dual action of tirapazamine in the induction of DNA strand breaks. Cancer Res, 1996: 56:1584-1590.

15. Brown JM. The hypoxic cell: a target for selective cancer therapy- Eighteenth Bruce F. Cain Memorial Award Lecture. Cancer Res, 1999; 59:5863-5870.
16. Ganley B, Chowdhury G, Bhansali J, Daniels JS. Gates KS. Redox-activated, hypoxia-selective DNA cleavage by quinoxaline 1,4-di-N-oxides. Bioorg Med Chem, 2001; 9:2395-2401.

17. Monge A, Martinez-Crespo FJ, Lopez de Certain A, Palop JA, Narro S, Senador V, Marin A, Sainz Y, Gonzalez M, Hamilton E, Barker AJ, Clarke ED, Greenhow DT. Hypoxia-selective agents derived from 2-quinoxalinecarbonitrile 1,4-di-N-oxides. J Med Chem, 1995; 38:4488-4494.

18. K.O. Hicks KO, Y. Fleming Y, B.G. Siim BG, C.J. Koch CJ, W.R. Wilson WR. Extravascular diffusion of tirapazamine: effect of metabolic consumption assessed using the multicellular layer model. Int J Radiat Oncol Biol Phys, 1998; 42:641-649.

19. Hicks KO, Myint H, Patterson AV, Pruijn FB, Siim BG, Patel K, Wilson WR. Oxygen dependence and extravascular transport of hypoxia-activated prodrugs: comparison of the dinitrobenzamide mustard PR-104A and tirapazamine. Int J Radiat Oncol Biol Phys, 2007; 69:560-571.

20. Pruijn FB, Sturman J, Liyanage S, Hicks KO, Hay MP, Wilson WR. Extravascular transport of drugs in tumor tissue: Effect of lipophilicity on diffusion of tirapazamine analogues in multicellular layer cultures. J Med Chem, 2005; 48:1079-1087.

21. Hay MP, Gamage SA, Kovacs MS, Pruijn FB, Anderson RF, Patterson AV, Wilson WR, Brown JM, Denny WA. Structure-activity relationship of 1,2,4-benzotiriazine 1,4-dioxides as hypoxiaselective analogues of tirapazamine. J Med Chem, 2003; 46:169-182.

22. Anderson RF, Harris TA, Hay MP, Denny WA. Enhanced conversion of DNA radical damage to double strand breaks by 1,2,4-benzotriazine 14dioxides linked to a DNA binder compared to tirapazamine. Chem Res Toxicol, 2003; 16:14771483.

23. Hay MP, Hicks KO, Pchalek K, Lee HH, Blaser A, Pruijn FB, Anderson RF, Shinde SS, , Wilson, WR, Denny WA. Tricyclic $[1,2,4]$ triazine 1,4-dioxides as hypoxia selective cytotoxins. J Med Chem, 2008; 51:6853-6865.

24. Hay MP, Pchalek K, Pruijn FB, Hicks KO, Siim BG, Anderson RF, Shinde SS, Phillips V, Denny WA, Wilson WR. Hypoxia-selective 3-alkyl 1,2,4benzotriazine 1,4-dioxides: the influence of hydrogen bond donors on extravascular transport and antitumor activity. J Med Chem, 2007; 50:66546664.

25. Hay MP, Hicks KO, Pruijn FB, Pchalek K, Siim BG, Wilson WR, Denny WA. Pharmacokinetic/pharmacodynamic model-guided identification of hypoxia-selective 1,2,4benzotriazine 1,4-dioxides with antitumor activity: the role of extravascular transport. J Med Chem, 2007; 50:6392-6404. 
26. Elsaidi H, Ahmadi F, Kumar P, Wiebe L. Development of $\left[{ }^{131} \mathrm{I}\right] \mathrm{I}-\mathrm{EOE}-\mathrm{TPZ}$ and $\left[{ }^{131} \mathrm{I}\right] \mathrm{I}-\mathrm{EOE}-$ TPZMO: Novel tirapazamine (TPZ)-based radioiodinated pharmaceuticals for application in theranostic management of hypoxia. Pharmaceuticals, 2019; 12: 3.

27. Elsaidi HRH, Yang X-H, Ahmadi F, Weinfeld M, Wiebe LI, Kumar P. Putative electron-affinic radiosensitizers and markers of hypoxic tissue: synthesis and preliminary in vitro biological characterization of C3-amino-substituted benzotriazine dioxides (BTDOs). Eur J Med Chem, 2019; 165:216-224.

28. Nocentini A, Trallori E, Singh S, Lomelino CL, Bartolucci G, Mannelli LD-C, Ghelardini C, McKenna R, Gratteri P, Supuran CT. 4-Hydroxy-3nitro-5-ureido-benzenesulfonamides selectively target the tumor-associated carbonic anhydrase isoforms IX and XII showing hypoxia-enhanced antiproliferative profiles. J Med Chem, 2018; 61:10860-10874.

29. Shen X, Laber CH, Sarkar U, Galazzi F, Johnson KM, Mahieu NG, Hillebrand R, Fuchs-Knotts T, Barnes CL, Baker GA, Gates KS. Exploiting the inherent photophysical properties of the major tirapazamine metabolite in the development of profluorescent substrates for enzymes that catalyze the bioreductive activation of hypoxia-selective anticancer prodrugs. J Org Chem, 2018; 83:31263131.

30. Shah Z, Mahbuba R, Turcotte B. The anticancer drug tirapazamine has antimicrobial activity against Escherichia coli, Staphylococcus aureus and Clostridium difficile, FEMS Microbiol Lett, 2013; 347:61-69.

31. Chopra S, Koolpe GA, Tambo-Ong AA, Matsuyama KN, Ryan KJ, Tran TB, Doppalapudi RS, Riccio ES, Iyer LV, Green CE, Wan B, Franzblau SG, Madrid PB. Discovery and optimization of benzotriazine di$\mathrm{N}$-oxides targeting replicating and nonreplicating mycobacterium tuberculosis. J Med Chem, 2012; 55:6047-6060.

32. Maccoll A. Reduction potentials of conjugated systems. Nature, 1949; 163:178-179.

33. Winget $\mathrm{P}$, Weber EJ, Cramer CJ, Truhlar DG. Computational electrochemistry: aqueous oneelectron oxidation potentials for substituted anilines. Phys Chem Chem Phys, 2000; 2:1231-1239.

34. Baik M, Friesner RA. Computing redox potentials in solution: density functional theory as a tool for rational design of redox agents. J Phys Chem A, 2002; 106:7407-7412.

35. Schmidt AM, Busch M, Knapp EW. One-electron reduction potential for oxygen- and sulfur-centered organic radicals in protic and aprotic solvents. J Am Chem Soc, 2005; 127:15730-15737.

36. Cardona CM, Li W, Kaifer AE, Stockdale D, Bazan GC. Electrochemical considerations for determining absolute frontier orbital energy levels of conjugated polymers for solar cell applications. Adv Mater, 2011; 23:2367-2371.

37. Davis AP, Fry AJ. Experimental and computed absolute redox potentials of polycyclic aromatic hydrocarbons are highly linearly correlated over a wide range of structures and potentials. J Phys Chem A, 2010; 114:12299-12304.

38. Speelman AL, Gillmore JG. Efficient computational methods for accurately predicting reduction potentials of organic molecules. J Phys Chem A, 2008; 112:5684-5690.

39. Lynch AJ, Speelman AL, Curry BA, Murillo CS, Gillmore JG. Expanding and testing a computational method for predicting the ground state reduction potentials of organic molecules on the basis of empirical correlation to experiment. J Org Chem, 2012; 77:6423-6430.

40. Méndez-Hernández DD, Tarakeshwar P, Gust D, Moore TA, Moore AL, Mujica V. Simple and accurate correlation of experimental redox potentials and DFT-calculated HOMO/LUMO energies of polycyclic aromatic hydrocarbons. J Mol Model, 2013; 19:2845-2848.

41. Méndez-Hernándeza DD, Gillmore JG, Montanoa LA, Gusta D, Moore TA, Moore AL, Mujica VJ. Building and testing correlations for the estimation of one-electron reduction potentials of a diverse set of organic molecules. J Phys Org Chem, 2015; 28:320-328.

42. Shao $\mathrm{Y}$ et al. Advances in methods and algorithms in a modern quantum chemistry program package. Phys Chem Chem Phys, 2006; 8:3172-3191.

43. Shao $\mathrm{Y}$ et al. Advances in molecular quantum chemistry contained in the Q-Chem 4 program package. Mol. Phys, 2015; 113:184-215.

44. Barone V, Cossi M. Quantum calculation of molecular energies and energy gradients in solution by a conductor solvent model. J Phys Chem A, 1998; 102:1995-2001.

45. Cossi M, Rega N, Scalmani G, Barone V. Energies, structures, and electronic properties of molecules in solution with the CPCM solvation model. J Comput Chem, 2003; 24:669-681.

46. Lee C, Yang W, Parr RG. Development of the ColleSalvetti correlation-energy formula into a functional of the electron density. Phys Rev, 1988; B 37:785789.

47. Becke AD. Perspective on "Density functional thermochemistry. III. The role of exact exchange. J Chem Phys, 1993; 98:5648-5652.

48. Harihan PC, People JA. The influence of polarization functions on molecular orbital hydrogenation energies. Theor Chim Acta, 1973; 28:213-222. 
49. Hariharan PC, People JA. The effect of d-functions on molecular orbital energies for hydrocarbons. Chem Phys Lett, 1972; 16:217-219.

50. Francl MM, Pietro WJ, Hehre WJ, Binkley JS, Gordon MS, DeFree DJ, People JA. Self-consistent molecular orbital methods. XXIII. A polarizationtype basis set for second-row elements. J Chem Phys, 1982; 77:3654-3665.

51. Patel KB, Wilson RL. Semiquinone free radicals and oxygen. Pulse radiolysis study of one electron equilibria. J Chem Soc Faraday Trans, $1973 ; 89: 814-819$.

52. Wardman P. Reduction potentials of one-electron couples involving free radicals in aqueous solution. J Phys Chem, 1989; 18:1637-1755.

53. G.E. Adams GE, E.D. Clarke ED, I.R. Flockhart IR, R.S. Jacobs RS, D, S. Sehmi DS, I.J. Stratford IJ, P. Wardman P, M.E. Watts ME. Structure-activity relationships in the development of hypoxic cell radiosensitizers: I. Sensitization efficiency. Int J Radiat Biol, 1979; 35:133-150. 